\title{
Democracia, organización y participación de las mujeres: un proceso de construcción de una ciudadanía diferente*
}

\author{
Rebeca E. Madriz Franco*
}

Recibido: 30 de septiembre de 2019 • Aprobado: 3 de noviembre de 2019

\section{Resumen}

La democracia - en su concepción clásica como forma de gobierno - ha venido transformándose en diversos contextos históricos, adquiriendo sentidos que dan cuenta de su carácter performativo. En Venezuela, la organización social e institucional ha sido impactada por una forma de democracia, definida constitucionalmente como participativa y protagónica. Gracias a la participación protagónica, las mujeres vienen ocupando un rol fundamental en la organización social y política, denotando ser un dispositivo capaz de incidir en la construcción de una ciudadanía que contribuya a desmonopolizar el poder político que hasta ahora sigue siendo patriarcal. Las relaciones hegemónicas de poder siguen siendo androcéntricas, aun cuando la revolución de las mujeres hace del feminismo uno de los movimientos sociales más fuertes del mundo occidental. Ahora bien, en relación con el debate democrático, la teoría feminista se manifiesta mediante dos posturas fundamentales: a) ganar terreno ante la visión universalista de la ciudadanía, o b) visibilizar la especificidad para denunciar la dominación patriarcal que hace de la diferencia sexual un factor de discriminación social. Este trabajo pretende estudiar cómo han ocurrido estos procesos y cómo, mediante la participación protagónica, se ha dado una transformación sustancial en la ampliación de los derechos ciudadanos de las venezolanas.

Palabras clave: ciudadanía, democracia, feminismo, movimiento de mujeres, participación.

\footnotetext{
Artículo de reflexión. Elaborado en el marco del proyecto de investigación de tesis doctoral, del programa de Estudios de la Organización de la Universidad Nacional Experimental Simón Rodríguez. Citar como: Madriz, R. (2020). Democracia, organización y participación de las mujeres: un proceso de construcción de una ciudadanía diferente. Análisis, 52(96), 21-44. Dol: https://doi.org/10.15332/21459169/5333

- Abogada por la Universidad de Carabobo, cursante del Doctorado en Estudios de la Organización por la Universidad Nacional Experimental Simón Rodríguez (UNESR). Directora General de la Fundación Género con Clase. Dirección postal: Rectorado UNESR, Urbanización Santa Fe, 1060, Caracas, Venezuela. Correo electrónico: rebecamadrizfranco@gmail. com. ORCID: https://orcid.org/0000-0002-3732-3001
} 


\section{Democracy, organization and participation of women: a process of building a different citizenship}

Rebeca E. Madriz Franco

\section{A bstract}

Democracy - in its classical conception as a form of government - has been transforming itself into diverse historical contexts, acquiring senses that account for its performative character. In Venezuela, the social and institutional organization has been impacted by a form of democracy, constitutionally defined as participatory and leading. Thanks to the leading role played, women have been occupying a fundamental role in the social and political organization, denoting being a device capable of influencing the construction of a citizenship that helps to demolish the political power that until now remains patriarchal. Hegemonic power relations remain androcentric, even though the women's revolution makes feminism one of the strongest social movements in the Western world. Now, in relation to the democratic debate, feminist theory manifests itself through two fundamental positions: a) gaining ground in the face of the universalistic vision of citizenship, or b) making visible the specificity to denounce the patriarchal domination that makes sexual difference a factor of social discrimination. This paper intends to study how these processes have occurred and how, through leading participation, there has been a substantial transformation in the extension of citizen rights of Venezuelan women.

Keywords: citizenship, democracy, feminism, women's movement, participation. 


\title{
Démocratie, organisation et participation des femmes : le processus de construction d'une nouvelle citoyenneté
}

\author{
Rebeca E. Madriz Franco
}

\section{Résumé}

La démocratie - dans sa conception classique comme forme de gouvernements'est transformé historiquement, ce qui rend compte de son caractère performatif. $\mathrm{Au}$ Venezuela, l'organisation sociale et institutionnelle a été modifiée par une forme de la démocratie conçue constitutionnellement comme participative et du « rôle principal ». Grâce à cette condition le rôle des femmes est de plus en plus important dans la vie sociale et politique, ce qui leur permet de contribuer à une citoyenneté capable de rompre le monopole patriarcal du pouvoir politique. Les rapports de force restent andro-centriques, même si la révolution des femmes fait du féminisme l'un des principaux mouvements sociaux d'aujourd'hui. Or, à propos de la démocratie, la théorie féministe repose sur deux positions principales : a) gagner du terrain face à la vision universaliste de la démocratie ; b) rendre visible la domination patriarcale qui fait de la différence sexuelle un facteur de discrimination sociale. Ce travail se propose d'étudier le développement de ces processus et de savoir si, par la participation « du premier rôle », a pu avoir lieu une transformation conséquente en ce qui concerne de droits des citoyennes vénézuéliennes.

Mots clés: citoyenneté, démocratie, féminisme, mouvement des femmes, participation. 


\section{Introducción}

Democracia no es un concepto unívoco, aséptico; es más bien un concepto que debe estar siempre contextualizado histórica y teóricamente. Al profundizar en su definición, encontramos que la mayoría de las autoras y autores se refiere a esta como una forma de gobierno que se ha instituido como paradigma de la modernidad, pero que por su carácter performativo puede expresarse de formas disímiles, desde la legitimación de las más atroces formas de exclusión, hasta desafiando las relaciones de poder del orden hegemónico. En este sentido, García-Linera (2014) señala que "no existe la 'verdadera' y definitiva definición de democracia, transhistórica y objetiva. Lo que se entiende por democracia en un momento dado es siempre una convención histórica, un producto provisional de intersubjetivaciones resultantes de distintos modos de acción comunicativa" (p. 14), advirtiendo más adelante la desigualdad que existe entre definiciones dominantes y subalternas, lo que De Sousa-Santos (2018) complementa con la siguiente afirmación:

No hay sociedades democráticas: hay sociedades que, siendo gobernadas por la izquierda, están en proceso de democratización y, cuando son gobernadas por la derecha, en proceso de fascistización. Gobernar hacia la izquierda es ampliar la democracia tanto en las relaciones políticas como en las relaciones sociales. Gobernar hacia la derecha es restringir la democracia en esas mismas relaciones. (p. 509)

Partiendo de estos enfoques, y las múltiples definiciones que se hacen de la democracia, nos remitiremos a las diversas visiones y aportes sobre dos tipos de democracia tomando en cuenta el contexto venezolano: la democracia representativa y la democracia participativa, y el papel que le ha tocado jugar a las mujeres, entendiendo además que existen diversas visiones en la teoría crítica que problematizan los diferentes enfoques sobre democracia.

Para la teoría feminista, nos dice Silva-Charvet (2005) que "se ha definido la democracia con distintos adjetivos: radical, participatoria, paritaria o plural. Más allá de sus particularidades, su sentido común es que todas ellas proponen una profundización y radicalización de la concepción sustantiva de la democracia" (p. 34). El contenido feminista que le da carácter sustantivo a esa democracia para Carole Pateman es su carácter "descentralizado, anti-jerárquico, colectivo, libre, horizontal, participativo y cooperativo" (citada por Silva-Charvet, 2005, p. 35). Desde el enfoque feminista, la democracia debe expresar entonces un conjunto de valores que son característicos de la organización feminista.

Desmonopolizar la política también implica feminizarla, porque el poder históricamente ha estado masculinizado y, en ese sentido, las mujeres deberían tener - en un escenario democrático - la posibilidad de incorporarse al ejercicio del poder político en las mismas condiciones, si la perspectiva de este es desde un enfoque de igualdad sustantiva. 
Desde esta mirada, hacer un balance de las democracias, especialmente en América Latina y el Caribe, resulta complejo, pues en un continente marcado por las brechas más grandes de desigualdad los sujetos subalternos siguen teniendo barreras no solo en el ejercicio del poder, sino en la valoración de los saberes de un pueblo, cuya carga histórica fue devastada por la herencia colonial y patriarcal.

Laclau (citado por Dussel, 2010) señala que "la tarea no es ya la revolución anticapitalista, sino la democracia radical" (p. 125), una democracia en la que el sujeto histórico, de articulación, ya no es la clase obrera "como última instancia sino que 'aparecen ahora nuevos antagonismos: [...] los movimientos sociales' [...] que para Laclau 'no deben renunciar a la ideología liberal-democrática, sino al contrario, profundizarla y transformarla en una democracia plural"' (p. 126).

Esa forma plural es relevante porque, cuando la teoría feminista interpela la democracia, lo hace desde la posición histórica de subordinación que le ha otorgado el patriarcado a las mujeres, donde la dimensión de "lo privado" ha sostenido las más grandes injusticias y vejaciones sobre la mitad de la población humana, silenciada en un pacto patriarcal que ha distribuido el poder de forma asimétrica y desigual, por lo que desde la mirada feminista la profundización democrática pasa por el acceso y reconocimiento de los aportes de las mujeres a la sociedad.

Entender la democracia participativa y protagónica como sinónimo también de la democracia sustantiva, radical, plural, implica poner la mirada sobre lo que advierte Iris Marion Young cuando señala que "al querer imponer una idea universalizadora de lo que es participar y deliberar, se estaría llevando a cabo un acto de poder y excluyendo a quien no tiene capacidad de significar" (MartínezPalacios, 2018, p. 3). Para las mujeres - al estar excluidas de lo político- ha quedado limitada esa cualidad de representar ideas o propuestas, o estas no han sido suficientemente reconocidas y valoradas, por lo que es necesario profundizar en cómo viven y experimentan las mujeres la participación protagónica.

\section{Caracterización de la situación venezolana}

La Constitución venezolana de 1961 establecía en sus artículos 3 y 4 que "el gobierno de la República de Venezuela es y será siempre democrático, representativo, responsable y alternativo" y que "la Soberanía reside en el pueblo, quien la ejerce, mediante el sufragio, por los órganos del Poder Público", respectivamente. De este modo, limitaba la participación de las ciudadanas y ciudadanos a un modelo de democracia representativa, ejercida a través de los representantes elegidos mediante el ejercicio del derecho al voto, en el que las mujeres tenían una escasa visibilidad y la participación popular tenía una expresión limitada a cada proceso electoral o a la libertad de reunión. No debe olvidarse que, como lo plantea Falcón (2000), la "conquista del voto no cambia, en ningún país, el papel subordinado que las mujeres siguen teniendo asignado" (p. 25). 
Posteriormente, con la Constitución de la República Bolivariana de Venezuela (CRBv) de 1999, se estableció en su artículo 5 lo siguiente:

La soberanía reside intransferiblemente en el pueblo, quien la ejerce directamente en la forma prevista en esta Constitución y en la ley, e indirectamente, mediante el sufragio, por los órganos que ejercen el Poder Público. Los órganos del Estado emanan de la soberanía popular y a ella están sometidos. (CRBV, 1999)

En este sentido, es un desafío profundizar desde una perspectiva feminista cómo es el ejercicio de esa soberanía para las mujeres, cómo esta ha incidido en su vida, cómo se expresa esa soberanía popular desde las mujeres.

El artículo 6 de la Constitución señala lo siguiente: “El gobierno de la República Bolivariana de Venezuela y de las entidades políticas que la componen es y será siempre democrático, participativo, electivo, descentralizado, alternativo, responsable, pluralista y de mandatos revocables".

Mientras que en el artículo 62 se amplía este enfoque en los siguientes términos:

Todos los ciudadanos y ciudadanas tienen el derecho de participar libremente en los asuntos públicos, directamente o por medio de sus representantes elegidos o elegidas. La participación del pueblo en la formación, ejecución y control de la gestión pública es el medio necesario para lograr el protagonismo que garantice su completo desarrollo, tanto individual como colectivo. Es obligación del Estado y deber de la sociedad facilitar la generación de las condiciones más favorables para su práctica.

Finalmente, respecto a los medios de participación, el artículo 70 establece lo siguiente:

Son medios de participación y protagonismo del pueblo en ejercicio de su soberanía, en lo político: la elección de cargos públicos, el referendo, la consulta popular, la revocación del mandato, las iniciativas legislativas, constitucional y constituyente, el cabildo abierto y la asamblea de ciudadanos y ciudadanas cuyas decisiones serán de carácter vinculante, entre otros; y en lo social y económico, las instancias de atención ciudadana, la autogestión, la cogestión, las cooperativas en todas sus formas incluyendo las de carácter financiero, las cajas de ahorro, la empresa comunitaria y demás formas asociativas guiadas por los valores de la mutua cooperación y la solidaridad.

El modelo de democracia participativa y protagónica desarrollada en Venezuela a partir de la Constitución de 1999 ha permitido generar un contexto de importantes avances y profundización del modelo democrático. La participación protagónica ha sido el eje central a partir del cual se han configurado formas de ejercicio de la democracia y de manifestación de la ciudadanía, profundizadas 
a lo largo de las etapas que ha venido atravesando el país desde este cambio paradigmático que ha impactado en la vida pública y política, en la vida de las ciudadanas y ciudadanos con un énfasis particular en la masiva participación protagónica que han venido teniendo las mujeres. Ahora bien, es importante definir qué se ha entendido por participación protagónica $y$, en especial para las mujeres, qué implicaciones ha tenido sobre ellas como colectivo el hecho de participar activamente en diversos procesos políticos en los últimos años.

La profundización de este modelo se observa nítidamente en los distintos planes nacionales del país. Así, en el Plan Nacional Simón Bolívar 2007-2013 (Ministerio del Poder Popular para la Comunicación y la Información, 2009), en su objetivo III-2.1, se plantea lo siguiente: "Alcanzar irrevocablemente la democracia protagónica revolucionaria, en la cual la mayoría soberana personifique el proceso sustantivo de toma de decisiones".

Esta línea es ratificada en el Segundo Plan de Desarrollo Económico y Social de la Nación 2013-2019 (2013), cuyo objetivo estratégico y general 2.5.1 establece lo siguiente: "Desatar la potencia contenida en la Constitución Bolivariana para el ejercicio de la democracia participativa y protagónica".

En esta misma línea histórica, el más reciente Plan Socialista de Desarrollo Económico y Social de la Nación 2019-2025 (2019) señala, en su objetivo 2.2, “Garantizar la inclusión plena y protagónica de todos los sectores de la sociedad en el desarrollo integral de la democracia en sus cinco dimensiones", siendo consideradas las dimensiones económica, social, espacial, política y cultural. Además, destaca inmediatamente después, en su objetivo 2.2.1.1, "Profundizar la participación política y protagónica de las mujeres en la sociedad", aspecto a partir del cual centraremos la atención para definir, profundizar y dimensionar su incidencia en el proyecto personal y colectivo de las mujeres en Venezuela en los últimos 20 años, siendo pertinente para los desafíos nacionales, en la medida en que contribuye de manera directa al Plan Sectorial para la Igualdad y la Equidad de Género “Mamá Rosa 2013-2019” (Ministerio del Poder Popular para la Mujer y la Igualdad de Género, 2013).

En la actualidad, Venezuela cuenta con un significativo movimiento de mujeres. El fortalecimiento de este movimiento social se ha visto estimulado debido a que, dentro de los avances alcanzados en los últimos 20 años, las Leyes del Poder Popular se han convertido en un novedoso bloque de medidas de carácter legislativo que buscan instrumentalizar el modelo de democracia participativa y protagónica mediante un conjunto de mecanismos de participación inéditos, radicales en algunos casos. Asimismo, un conjunto de acciones de carácter político, social y ejecutivo han venido apostando al desarrollo de este modelo de democracia; sin embargo, las tramas de poder siguen estando permeadas por unas formas de representación política que no son proporcionales a la masiva participación popular, en este caso la de las mujeres.

Basta estudiar la composición de la mayoría de los poderes públicos, así como de las direcciones gremiales y empresariales, para constatar que las mujeres 
venezolanas todavía constituyen una minoría en los espacios de conducción estratégica de la sociedad (García-Prince, 2012). Estos espacios de conducción estratégica siguen estando masculinizados, pues las más significativas experiencias de protagonismo popular que se han experimentado, especialmente a través de los consejos comunales y comunas, no trascienden su escenario local. La participación de las mujeres se da de manera masiva en lo local, pero en la medida en que cambia el rango de la territorialidad su representación es cada vez menor, por un lado, poniendo en cuestionamiento la beligerancia del movimiento de mujeres, pero por otro - como aspecto de mayor interés para esta investigación-, haciendo necesario plantearse qué es participar para las mujeres venezolanas.

Si bien es cierto que la participación protagónica en Venezuela irrumpió en el debate democrático a partir de 1999 como un elemento estructural de la democracia, constituyéndose en un paradigma democrático de este tiempo, aún tiene importantes desafíos. Los sectores femeninos y demás grupos subalternos se topan (tal como ha definido la teoría feminista en el caso de las mujeres) con un techo de cristal que les impide trascender a espacios de mayor incidencia en la toma de decisiones, que siguen manteniendo un orden jerárquico, diferenciado, aun cuando estén sostenidos sobre la legitimidad que otorga la participación protagónica de las mayorías. Por ello, es importante estudiar los niveles de participación protagónica de las mujeres tanto en los espacios comunales y locales como en los espacios medios y nacionales, pues la relación que quiebra y produce una disparidad en esa relación es relevante para caracterizar los desafíos del modelo político venezolano.

Monedero (2012) señala que la democracia debe responder a un conjunto de requisitos ligados a la participación:

Si bien el Estado debe dar cuenta de la organización colectiva sobre la base de las leyes, corresponde a la sociedad civil (los movimientos sociales y colectividades organizadas), a través de la democracia deliberativa y la creación de una opinión pública informada, tres aspectos: (1) crear espacios más amplios para la acción social (presentar problemas negados por el sistema político); (2) hacer públicas las diferencias de identidad y exigir reconocimiento de la diferencia (como plantea Balibar, "viajar en la identidad"); (3) ampliar la forma de la política poniendo en la agenda aspectos que deben politizarse (no estatalizarse), esto es, incorporando a la polis las cuestiones que estaban recluidas en el ámbito privado. (p. 278)

Estos tres aspectos señalados por Monedero (2012) resultan vitales para un análisis feminista, pues apuntan a dos aspectos medulares:

1. El reconocimiento de la diferencia: ha formado parte fundamental del debate de los feminismos de la igualdad y la diferencia que, aunque superados en términos teóricos, se expresa en la acción concreta y exige, entre otras cosas: a) no demandar exclusivamente igualdad con los hombres, entendida 
como igualación sobre la base de un modelo que ha tenido al varón como parámetro de la humanidad, y b) el reconocimiento de los aportes propios de las mujeres, desde una praxis histórica que ha estado al margen, pero que tiene su propia contribución a otras formas de entender y vivir las relaciones sociales en todos los ámbitos.

2. Ampliar la forma de la política y politizar lo privado, que ha sido una de las principales demandas y aportes de los feminismos, sintetizado en la popular frase: "lo personal es político", para denunciar que las relaciones de dominación y esclavitud que se dan en el ámbito privado encarnan los más grandes antagonismos de la sociedad de clases, que han mantenido sobre el cuerpo y la sexualidad femenina la opresión y la violencia patriarcal hacia las mujeres. Lo personal es político, porque la familia monogámica patriarcal constituye la principal célula de reproducción de las desigualdades sociales, cuya máxima expresión jerárquica del poder es encarnada por el pater familias, ya que su transformación radical puede contribuir al establecimiento de relaciones más igualitarias y sociedades sustancialmente más democráticas.

Hoy parecieran darse cambios importantes en la subjetividad de las mujeres respecto al poder, tal y como lo señala Carosio y Vargas-Arenas (2010):

Un anhelo político marca cambios en las identidades de cada vez más latinoamericanas: es el deseo de poder. Su emergencia en la subjetividad femenina es ya una muestra del trastocamiento del orden patriarcal. El poder tiene marca y rostro masculino, pero estamos viendo al poder resignificado feministamente en la práctica política de millones de mujeres latinoamericanas. Se trata de una reestructuración del campo político desde la propuesta feminista para inventar formas de convivencia y creación de futuro desde una perspectiva de buen vivir y sostenibilidad de la vida. (p. 86)

Esto da cuenta de que, dentro de los cambios importantes atribuibles a la participación, está el fortalecimiento de la determinación de las mujeres por irrumpir cada vez con mayor fuerza al ámbito político y en los espacios de poder, e incluso atreverse a reivindicar nuevas relaciones y nuevas instancias de poder.

\section{El debate feminista sobre la democracia}

En este sentido, como denuncia a las milenarias formas de poder patriarcal y las perspectivas de la democracia sustantiva, el feminismo incorpora al debate político la democracia de género o paritaria que se plantea como parte de los desafíos democráticos de la actualidad. De este modo, se identifican diversas formas de equiparar las desigualdades históricas que pesan sobre las mujeres; una de ellas es la disparidad política. En este orden, una de las propuestas más recurrentes ha sido la de los sistemas de cuotas que tienden a establecer porcentajes de participación (en algunos casos obligatorios) para incrementar la participación/ 
representación femenina en los espacios de poder y toma de decisiones. Esta es una de las principales banderas de los movimientos de mujeres en todo el mundo, para lograr la materialización en el acceso a los espacios de toma de decisiones de forma equitativa, como expresión de la expansión de la ciudadanía, tarea prioritaria en la construcción de un orden democrático y plural.

En el caso venezolano, pese a la masiva participación protagónica de las mujeres, aún no ha sido posible alcanzar mayores niveles de representación política, y nos preguntamos: ¿podemos hablar de participación protagónica sin tener una representación proporcional de las mujeres en los espacios de toma de decisiones? ¿Es en la esfera del poder constituido donde se puede evidenciar el nivel de participación protagónica de las mujeres? ¿O es que participación y representación implican una unidad contradictoria que puede permitir profundizar la democratización del poder y la feminización de la política?

Para ello, vamos a la definición de Silva-Charvet (2005) sobre política, en la que afirma lo siguiente:

En su acepción clásica podría definirse la política como una práctica orientada a la lucha por el poder. Por consiguiente, su ejercicio comportaría participación, otro concepto [...] íntimamente ligado al de democracia y ciudadanía. En efecto, los/as ciudadanos/as existen en cuanto se autodeterminan, es decir, en cuanto tienen identidad, deciden y actúan en función de su voluntad y sus intereses. En sentido lato, se podría definir la participación como la intervención en procesos de decisión. (p. 40)

Visto desde esta perspectiva, la participación de las mujeres en Venezuela y su cualidad protagónica es un hecho significativo. Sin embargo, pareciera que su incidencia se produce fundamentalmente en lo local y tiene muchas veces un carácter utilitario, de poca trascendencia en las estructuras consideradas formales y tradicionales de poder.

Pese a que la participación protagónica de las mujeres pareciera determinante en el carácter democrático de la sociedad venezolana, se enfrentan a una infravaloración que las ubica siempre al servicio de los otros, en un ámbito más de acción social que de decisiones macro de la política. Es decir, sigue teniendo un carácter secundario en el imaginario social, a pesar de ser sostenedoras de las condiciones que hacen posible relaciones sociales más democráticas en el ámbito comunitario, con una incidencia concreta en la resolución de los problemas comunes. Dicha participación se da fundamentalmente a nivel de los microespacios sectoriales donde, según Laclau (citado por Di Marco, 2011), "las nuevas fuerzas históricas se constituyen" (p. 311).

Es crucial estudiar entonces la participación protagónica de las mujeres como fuerza histórica, como potencial democratizador que puede otorgar a la sociedad aportes sustantivos para el fortalecimiento de la democracia venezolana, como lo señala García-Linera (2014): 
Democracia es, entonces, ampliación de lo político, creciente ruptura de los monopolios de la política, continua renovación de las instituciones políticas para dar paso a responsabilidades ampliadas de un número mayor de miembros de la sociedad. Democracia es movimiento, flujo, revocatoria, ampliación de la capacidad de decidir. Una sociedad es tanto más democrática cuantas más personas no sólo participan en la política sino también en la decisión de las maneras de participar... la democracia... es una comunitarización de la política que rompe la serialización y el disciplinamiento de cualquier norma rígida de acción política. (p. 33)

Acercándonos desde este enfoque a la experiencia venezolana, podemos hacer algunas aproximaciones a la participación protagónica, como un entramado de relaciones de poder que se producen desde actores sociales subalternos - en este caso las mujeres - , mediante acciones de incidencia en distintos espacios sociales, ejerciendo formas de autonomía no delegadas en la representación sino encarnadas en las propias protagonistas; así, se desconcentra el poder del Estado y se democratiza la acción ciudadana en torno a sus intereses, permitiéndoles ejercer decisiones directas en ámbitos de los que estuvieron históricamente excluidas.

De esta manera, la densa participación que protagonizan las mujeres venezolanas en los ámbitos comunitarios y locales puede ser un enclave necesario para garantizar una democracia sustantiva; de allí lo vital que resulta su análisis. Sin embargo, vale la pena incorporar como elementos resaltantes algunas caracterizaciones sobre las diversas formas de participación:

Tanto en la noción de participación de las teorías clásicas de la democracia cuanto en la que se deriva de las críticas deliberativas y participativas subyace la idea de que existen distintos tipos de participación organizados de manera jerárquica [...]. Las teorías sobre la participación que no son reflexivas con el poder simbólico estarían empleando una noción de participación que solo contempla lo que Cunill denomina participación política y participación ciudadana. Por consiguiente, estarían asignando un papel residual a la participación comunitaria y la participación social, tal y como las define la autora. (Martínez-Palacios, 2018, p. 9)

En este sentido, si democratizar el poder político es un objetivo macro, deconstruir las jerarquías en los tipos de participación podría ser una condición necesaria para lograrlo, pues todo parece indicar que los espacios de participación donde el protagonismo femenino es mayor son aquellos que tienen menor valoración social, pero a su vez más carga de trabajo y responsabilidades para las mujeres, expresándose en una triple jornada: doméstica, laboral (reconocida socialmente) y comunitaria.

De esta forma, responder a la pregunta ¿qué es participar para las mujeres venezolanas? resulta complejo desde una óptica feminista, porque el feminismo no 
tiene una visión homogénea en relación a este debate. Aquellos feminismos más afines a la igualdad (sean liberales o socialistas) reconocen que, aun cuando la participación de las mujeres se ha desarrollado significativamente en Venezuela (sobre todo a nivel de las bases sociales), estamos lejos de alcanzar la paridad política en los espacios decisivos de poder. Sin embargo, para aquellos feminismos que valoren más la diferencia o especificidad de la feminización de la política, el desarrollo de la participación política de las mujeres a nivel comunitario y local ha sido estratégico, porque ha impactado los niveles moleculares y microfísicos de las relaciones de poder.

Ahora bien, llama la atención que el sistema patriarcal, capitalista y colonial parece sufrir una mutación al extender la división sexual del trabajo del ámbito doméstico al ámbito comunitario (participación invisible o relacional), generando nuevas brechas que las separan del ámbito "público/político" (participación formal/visible). En este sentido, valorar y visibilizar la participación protagónica de las mujeres, así como contribuir a contener que esas brechas se acentúen, puede ser un aporte significativo para la democracia venezolana y para los proyectos emancipatorios globales.

En este sentido, Dussel (2011) nos aporta elementos claves para resignificar, a partir de un enfoque feminista, esta valoración que pareciera estar prevaleciendo, al afirmar que "el poder no es dominación, no es solo opresión, no es solo el poder como lo entiende la modernidad colonialista. Los nuevos movimientos sociales, y los antiguos movimientos clasistas y populares, necesitan teóricamente esta descripción positiva del poder" (p. 60).

Esa descripción positiva del poder es una necesidad y puede coadyuvar a seguir impulsando y dimensionar la importancia del protagonismo de las mujeres, pues la voluntad de participación en las venezolanas, entendida como "disciplina o actitud que se impone a los impulsos humanos para poder cooperar en la obra común" (Dussel, 2011, p. 408), es clara y significativa. Por lo tanto, el movimiento de mujeres puede ser un dinamizador clave de procesos de transformación sociales y democráticos, aunque hay que tomar en cuenta lo que señala Aguirre (2018):

La apuesta está en la real voluntad política de incluir la transversalidad de género... En caso contrario, las mujeres que participan de manera protagónica, si no ven cambios relevantes en las relaciones de poder y continúan encontrándose con el "techo de cristal" en los diferentes sectores, van a cuestionar y fijar posición frente a quienes toman las decisiones, sin incluirlas para avanzar en condiciones de igualdad, en la construcción de la matria-patria, bajo formas de relaciones de producción diferentes a las existentes, es decir, bajo una nueva división sexual del trabajo. (p. 111)

La voluntad de poder del propio movimiento de mujeres resulta medular, pero la voluntad política de quienes toman decisiones también, pues es necesario que comiencen a evidenciarse cambios en las relaciones desiguales de poder 
en correspondencia con el rol protagónico que han asumido las mujeres en Venezuela (Aguirre, 2018), como lo expresa Vargas-Arenas (2010): "Se han volcado a las calles a manifestar su apoyo, se han insertado en todas las misiones sociales, forman parte de los consejos comunales donde su presencia es del $60 \% "$ (p. 68).

\section{Participación protagónica de las mujeres y radicalización de la democracia}

La amplia participación femenina en Venezuela se da en un contexto general democrático que lo hace posible, que lo impulsa, y que pareciera haber servido como un instrumento transitorio para exigir hoy una nueva etapa en los niveles de participación y democratización del poder.

Al participar de manera protagónica las mujeres populares se van descubriendo a sí mismas, en su capacidad y en su potencia, van ganando en autoafirmación y también en reflexión sobre las múltiples opresiones y sobre su específica opresión de género, aunque todavía de manera un poco tímida y siempre con cierto temor a perder la aprobación masculina. (Carosio, 2012, p. 120)

Frente a eso nos preguntamos ¿cómo se expresa esa toma de conciencia de las mujeres frente a la opresión patriarcal? ¿Es la participación protagónica una vía para la emancipación femenina? Puede afirmarse que se ha venido evidenciando un proceso de empoderamiento que es individual y colectivo complementariamente, no fragmentado, y en el caso de las mujeres venezolanas puede verse con claridad lo siguiente:

Aunque las mujeres populares de las áreas urbanas se encuentran sumergidas en la lucha por la sobrevivencia como principal objetivo [...], al mismo tiempo se han transmutado en participar protagónicamente para asumir, como género, el control efectivo del proceso social bolivariano. (Vargas-Arenas, 2007, p. 190)

Es decir, el proceso de transformaciones democráticas en el país y el modelo de democracia participativa y protagónica parecen haber servido de escenario para potenciar los niveles de organización de los sectores femeninos. En el caso de las mujeres, estas representan la mitad de la población, y muchas veces la mitad de cada movimiento social. Pero indiscutiblemente la organización como mujeres ha sido un escenario radicalmente transformado desde 1999, siendo protagonistas de la construcción en distintos espacios de participación comunitarias, como los comités de salud, de tierras, los consejos comunales y en las misiones sociales.

Delgado (2017) resalta la creación de las siguientes instancias de mujeres en los últimos años: Red comunitaria contra la violencia a la mujer y la familia, Red de mujeres en altas funciones de gobierno, Fuerza Bolivariana de las Mujeres, 
Movimiento de Mujeres Clara Zetkin, Movimiento de Mujeres Manuela Sáenz (Momumas), Círculos de Mujeres Hacedoras de Cultura, Frentes de Mujeres Socialistas Bolivarianas, Frente Bicentenario de Mujeres y Movimiento de Mujeres Ana Soto, entre otros. Igualmente Delgado (2017) destaca "la constitución de 25.643 puntos de encuentro de Inamujer [...], los Comités de Madres del Barrio, [...] el surgimiento de nuevos agrupamientos y colectivos [...], que en 2010 coinciden en conformar la Araña Feminista" (p. 184).

De igual forma, debe destacarse el caso de la Unión Nacional de Mujeres, conformada por más de un millón de mujeres, cuyo documento programático denominado Documento base para el debate plataforma unitaria de lucha de las mujeres patriotas y revolucionarias (Congreso Venezolano de las Mujeres, 2015) es claramente antipatriarcal, incorpora de forma radical la agenda de lucha feminista, sintetiza la propuesta estratégica del Socialismo Feminista, y logra incorporar las necesidades prácticas y estratégicas de género. Por lo tanto, no podríamos afirmar que se trate de un movimiento de mujeres sin cualidad feminista. Lo que sí puede afirmarse es que la agenda feminista parece haberse flexibilizado frente a las agendas políticas coyunturales.

Desde el 2015, se ha exhortado en reiteradas ocasiones a cumplir criterios de paridad y alternabilidad política en los distintos procesos electorales que se han realizado. El 8 de marzo de 2017 se presenta ante la Asamblea Nacional Constituyente la propuesta de "Ley de Democracia Paritaria", que no ha sido sancionada hasta la fecha. En las elecciones municipales de 2018 el Consejo Nacional Electoral emitió una resolución de carácter obligatorio para las organizaciones con fines políticos, con el ánimo de garantizar este principio. Esa voluntad no trasciende lo declarativo, pues no coincide con un incremento sustancial de las mujeres en los espacios de toma de decisiones y de representación.

En este orden de ideas, también destaca la creación de espacios propios de las mujeres en los partidos políticos para promover, en cada instancia de base, organizaciones de articulación con el movimiento de mujeres, ampliando los escenarios de lucha política de las mujeres venezolanas. Esta experiencia ha impregnado especialmente partidos políticos adscritos a sectores de la izquierda venezolana.

En este sentido, es una deuda profundizar las complejidades de lo que viven las mujeres en Venezuela a partir del proceso de empoderamiento que han venido transitando en los últimos años, tanto individual como colectivamente, y atreverse, desde un posicionamiento crítico con voces propias, a mirarse en los feminismos latinoamericanos, sin perder de vista lo que afirman las bolivianas Paredes y Guzmán (2014), quienes señalan que "el feminismo para el feminismo comunitario es la lucha de cualquier mujer, en cualquier tiempo de la historia, en cualquier parte del mundo, que lucha o se rebela ante un patriarcado que la oprime o la quiere oprimir" (p. 67).

El feminismo latinoamericano hoy es protagonista fundamental de los pueblos que resisten, y el movimiento de las mujeres venezolanas tiene un cúmulo de 
aportes aun por visibilizar, porque el feminismo eurocentrado no tiene la última palabra, y las feministas en Bolivia así lo plantean:

Hemos hecho en el feminismocomunitario un largo recorrido desde hace años trayendo la memoria de nuestras abuelas, aprendiendo de la lucha de nuestros pueblos, pariendo y haciendo nuestra propuesta feminista en el proceso de cambio de Abya Yala, por eso era imprescindible una ruptura epistémica, hacer nuestras reconceptualizaciones y crear nuestra metodología, desde ahí nos reconocemos feministas, descolonizando el feminismo, desde ese lugar es que hablamos y decimos que hay feminismos sistémicos y antisistémicos. Con esto queremos decir que hay dos claves que hoy nos parecen principales, para que un feminismo $u$ otra lucha pueda ser antisistémica, estas claves son movimiento y propuesta de sociedad, si no hay movimiento, ni propuesta, la lucha puede quedarse en la resistencia, en la explicación, en la denuncia, en el esfuerzo aislado, localizado, que rápidamente es tragado, cooptado por el sistema, refuncionalizando los pedidos y al final no llegar a ser una lucha antisistémica, que no hace ni cosquillas al sistema ni a sus instituciones. (Paredes \& Guzmán, 2014, p. 56)

En Venezuela, sin lugar a dudas, existe un fuerte movimiento de mujeres, con una propuesta de sociedad y una ruta programática concreta. Queda por delinear de forma más clara la genealogía propia femenina y feminista, y cristalizar desde qué identidades se plantean y se nombran nuestros feminismos. En este orden, Vargas-Arenas (2007) expresa lo siguiente:

Las mujeres venezolanas, criollas campesinas, criollas populares urbanas, indígenas y de todas las clases sociales deben tomar conciencia que sus actitudes proclives a la participación y la lucha contemporáneas no son de gratis. El que hoy día asuman una actitud protagónica, se debe — en gran medida - a las tradiciones de luchas femeninas a lo largo de la historia; esas tradiciones no se inventan de un día para otro. (p. 199)

Recuperar esa memoria histórica es necesario para el movimiento de mujeres, porque pasa esencialmente por rescatar - sin pretender idealizar - la memoria colectiva de nuestras ancestras. Solo recientemente la tradición de lucha de las mujeres venezolanas, invisibilizada por la historiografía patriarcal, comienza a ser reivindicada y visibilizada; mientras no profundicemos en su reconstrucción, es difícil superar el sesgo discriminatorio. La memoria histórica es memoria colectiva y, sin referentes, las perspectivas históricas de los movimientos sociales pueden quedar desdibujadas. Además, escribir la historia de hoy puede contribuir a la profundización de las luchas feministas hacia el futuro.

Potenciar entonces la participación protagónica de las mujeres venezolanas pasa por fortalecer su proceso de empoderamiento, que según Aguirre (2018) se ha dado en dos fases: 
a) el empoderamiento desde la base, centrado en la organización popular, donde las mujeres se fueron fortaleciendo a partir de las políticas de inclusión social impulsadas desde un principio por el Gobierno Bolivariano, sin tener el acento de la transversalidad de género, y b) el empoderamiento como una política dirigida a las mujeres, cuya expresión son los programas [...] impulsados por el Ministerio de la Mujer. (p. 112)

Es decir, se debe dar un empoderamiento generado por el contexto democrático general y un empoderamiento direccionado, en buena medida, con una perspectiva feminista.

Para Carosio (2012), la participación no es inocua, sino que va elevando los niveles de conciencia de las mujeres y, a veinte años de experimentación y concreción de la democracia participativa y protagónica:

A medida que se va construyendo el poder popular, y con amplia participación de las mujeres, también va apareciendo una mayor conciencia de las determinaciones de género y la sujeción específica que implica, y va apareciendo la temática en reuniones, documentos y otros en los que se prefigura la transformación y emancipación. También va siendo cada vez más comprendida la relación entre socialismo y feminismo, se van posicionando consignas que mucho dicen el rumbo ideológico, tales como "sin feminismo no hay socialismo", "sin feminismo no hay revolución" que van cristalizando la conceptualización del socialismo feminista, hoy bandera del feminismo de izquierda venezolano. (Carosio, 2012, p. 121)

El que las mujeres no se ocupen de manera central de una agenda propia tiene que ver con que existe un condicionamiento de la sociedad hacia la maternidad social, pero este hecho no niega que puedan existir avances.

Carosio (2012) también plantea que "las mujeres hemos aportado al sostenimiento del sistema, y hemos terminado siendo un movimiento por la participación de las mujeres en lugar de la emancipación de las mujeres" (p. 14). Esta visión alerta sobre la necesidad de visibilizar e impulsar la agenda feminista, pero a su vez puede tener un potencial inmenso, no solo para el movimiento de mujeres, sino para la consolidación y profundización del modelo democrático venezolano.

En este sentido, podría afirmarse que se han conmovido levemente las bases de la cultura patriarcal, el imaginario colectivo sobre las mujeres es distinto, la tendencia organizativa es cada vez más creciente, con más o menos limitaciones la agenda feminista en diversos momentos se ha posicionado en el espacio público, pero no es suficiente.

Es menester potenciar la participación protagónica, ya que esta implica la acción individual y colectiva de las mujeres que puede desafiar las relaciones de poder patriarcal, a través de la incidencia directa y autónoma en los asuntos de su interés. 
El proyecto feminista plantea una revolución de la vida cotidiana que logre transformar las relaciones de poder que se dan en el espacio doméstico. El enfoque de la transversalidad de género es fundamental entonces para la superación de este sesgo androcéntrico:

No se trata de igualar a las mujeres con los hombres ni tampoco que las mujeres ocupen puestos de responsabilidad tradicionalmente reservados a los hombres para que se comporten de manera idéntica. Se trata de liberar la mirada femenina en lo que tal mirada signifique, incorporando esa versión del mundo a la tradicional masculina, automutilada al haber hurtado esa necesaria complementariedad. (Monedero, 2012, p. 283)

\section{Hacia una redefinición del concepto de ciudadanía}

Como se ha señalado, el feminismo no plantea simple igualación con los hombres, sino reconocimiento hacia la feminización de la sociedad. La condición genérica de las mujeres ha sido en buena medida el elemento por el que hemos sido incorporadas al ejercicio de la ciudadanía; por eso, queremos darle una mirada a este concepto con un enfoque feminista.

Para Pateman (citada por Carosio, 2010), "la ciudadanía es una categoría patriarcal" (p. 52) que inicia su desarrollo con la aparición histórica de la democracia y el republicanismo; nace con la política, entendida como la resolución colectiva de los problemas públicos, comprendiendo desde su definición una serie de derechos y deberes con el mantenimiento y fortalecimiento de la comunidad política del Estado, de los cuales las mujeres quedaron tempranamente excluidas.

Es con las grandes revoluciones burguesas, especialmente la Independencia de los Estados Unidos y la Revolución Francesa, que emerge la ciudadanía contemporánea, conceptualizada por los pensadores democráticos y liberales de la Ilustración. Así nace la Democracia Liberal Burguesa, con sus derechos y deberes ciudadanos. Esta forma de ciudadanía también será restringida solo a los hombres libres, con renta y alfabetizados, una democracia censitaria, patriarcal y clasista (Madriz-Franco, 2017). Para Silva-Charvet (2005) "la ciudadanía es un artefacto político-cultural propio de la modernidad; una estructura política universalizante a través de la cual el Estado burgués moderno desarrolla esa cualidad única de constituirse en el representante del interés general de la sociedad" (p. 37).

Un documento histórico de la respuesta de las mujeres a esa exclusión de los principios de libertad, igualdad y fraternidad fue la Declaración de los Derechos de la Mujer y la Ciudadana, donde Olympe de Gouges reclama iguales derechos para las mujeres, configurando el inicio de movimiento sufragista. 
En buena medida, el feminismo como movimiento social y político, ha dirigido sus esfuerzos en universalizar los derechos ciudadanos y humanos a todas las mujeres. El feminismo de la igualdad, ha centrado sus luchas y debates en lograr que las mujeres disfruten con los hombres de los mismos derechos políticos, sociales, económicos y culturales, la plena igualdad sustantiva y equidad de género siempre ha sido su objetivo estratégico. (Madriz-Franco, 2017, p. 105)

En este orden de ideas, Scott (2012) sostiene lo siguiente:

Las feministas cuestionaron la práctica de excluir a las mujeres de la ciudadanía. Afirmaron que no había una conexión lógica ni empírica entre el sexo y la capacidad de participar políticamente, y que la diferencia sexual no era un indicador de capacidad social, intelectual ni política. Sus argumentos eran vigorosos y convincentes [...]. Pero también eran paradójicos: para protestar contra la exclusión de las mujeres, debían actuar en su nombre $\mathrm{y}$, de ese modo, terminaban por invocar la misma diferencia que pretendían negar. [...]

¿Son las mujeres lo mismo que los hombres? ¿Esa mismidad es la única base sobre la cual puede afirmarse la igualdad? $¿ O$ son diferentes $y$, debido a sus diferencias o a pesar de ellas, tienen derecho a un tratamiento igualitario? (p. 12)

De esta visión crítica de la ciudadanía partimos para acercarnos a la idea de que la radicalización de la democracia venezolana puede necesitar entonces de una ampliación sustantiva de la ciudadanía de las mujeres.

En este sentido, es clave no negar la ciudadanía, sino asumirla como una categoría en construcción, en la que las mujeres tienen aún mucho por decir. Como lo afirman Vargas-Arenas y Sanoja-Obediente (2015), "la realidad actual venezolana nos dice que los movimientos sociales de nuestro pueblo están luchando por y redefiniendo lo que es el ejercicio de la ciudadanía. Cada movimiento social aspira [a] ejercer sus derechos, sobre todo los políticos, de manera directa" (p. 221); por eso entendemos la ciudadanía como un proceso que está en permanente tensión, inacabado, que desafía y debe desafiar las lógicas del poder patriarcal y colonial, y que debe ser asumido por las mujeres - como de hecho viene ocurriendo - en los términos aportados por García-Linera (2011):

El ciudadano no es un sujeto con derechos, aunque necesite de ellos para verificar su ciudadanía: ante todo es un sujeto que se asume como un sujeto con derechos políticos, que son correspondidos por la normatividad estatal, es decir, es un sujeto en estado de autoconciencia de ciertas facultades políticas. El acto de producir el derecho, de reconocerse activamente en él, es lo decisivo de su cualidad ciudadana, pues en el fondo no hay ciudadano al margen de la práctica de la ciudadanía, esto es, de la voluntad de intervenir en 
los asuntos que los vinculan a los demás conciudadanos. Estamos hablando entonces de la ciudadanía como responsabilidad política ejercida, como forma de intersubjetivación política. (p. 109)

Afirmar que las mujeres no hemos ejercido plenamente la ciudadanía y no podremos hacerlo mientras subsista la división sexual del trabajo no implica que renunciemos a la posibilidad de hacerlo; el feminismo como movimiento social y político ha dirigido sus esfuerzos en lograr el reconocimiento de los derechos ciudadanos y humanos para todas las mujeres. En ese recorrido histórico, se logró conquistar un conjunto de derechos que, sin duda, han ampliado en los últimos dos siglos de manera "intermitente" la ciudadanía de las mujeres; sin embargo, la mirada universal que sobre las luchas feministas ha imperado hasta ahora ha invisibilizado la experiencia propia del movimiento de mujeres y feminista desde América Latina y el Caribe, restándoles cualidad feminista y valor a las luchas y los aportes que se vienen produciendo con especial fuerza en los últimos años.

La voz del movimiento de mujeres es clave para identificar cómo se vive una participación protagónica desde las mujeres en el contexto venezolano, para visibilizar los aportes y resignificar las voces diversas de un liderazgo popular, masivo pero no hegemónico, que transforma en la cotidianidad aspectos medulares de otro mundo posible que se constituyen en un desafío frente a la globalización neoliberal. Es indispensable partir de la idea de que para los feminismos las jerarquías y clasificaciones son contrarias a su ética, con el fin de romper los sesgos que han pretendido y pretenden jerarquizar lo que es o no el feminismo vivido desde América Latina y el Caribe.

Finalmente, es en esta concepción que plantea el feminismo comunitario donde se presentan los principales desafíos de las organizaciones de mujeres en Venezuela, pues la autonomía del movimiento sigue siendo un debate pendiente que neutraliza en algunos momentos el potencial transformador de las mujeres. Las tensiones que se producen entre el ejercicio del poder y el movimiento de mujeres y feminista no tienen necesariamente que ser considerados antagónicos, sino que puede más bien encuadrar en lo que De Sousa Santos (2018) denomina democracia de alta intensidad.

Mientras tanto, sin autonomía, la agenda feminista puede seguir resultando incómoda y políticamente incorrecta, a pesar de que esta agenda puede traducirse en más democracia y justicia, pues el reconocimiento de la especificidad y la diferencia son relevantes mientras la hegemonía siga siendo ejercida por el sistema género colonial/moderno.

\section{A modo de conclusión}

A lo largo de este trabajo, hemos tratado de responder — no sin dificultad - las siguientes interrogantes: ¿cómo viven y experimentan las mujeres venezolanas la 
participación protagónica? ¿Qué se ha entendido por participación protagónica? ¿Cómo se expresa esa soberanía popular desde las mujeres? Y, en especial, ¿qué implicaciones ha tenido sobre ellas como colectivo el hecho de participar activamente en diversos procesos políticos en los últimos años? Otras interrogantes han sido: ¿podemos hablar de participación protagónica sin tener una representación proporcional de las mujeres en los espacios de toma de decisiones? ¿Es en la esfera del poder constituido donde se puede evidenciar el nivel de participación protagónica de las mujeres? ¿O es que participación y representación implican una unidad contradictoria que puede permitir profundizar la democratización del poder y la feminización de la política?

Para responder estas interrogantes, hemos desarrollado una serie de argumentos, que nos han llevado a dar ciertos rodeos, dando sensación de ambigüedad. Y es que para la teoría feminista no hay un consenso pleno en relación con el debate sobre la participación política, la democracia y los fines de la organización de las mujeres. El centro del debate se ha enmarcado en el reconocimiento de la diferencia y en ampliar la forma de la política, es decir, politizar lo privado. Dependiendo del posicionamiento desde el feminismo en relación con estos dos puntos de discusión, se pueden responder las interrogantes planteadas anteriormente.

Para aquellas posiciones feministas que responden a la tradición republicana (tanto liberal como socialista) y la justa lucha por la igualdad frente a los hombres, las mujeres venezolanas han dado pasos importantes en materia de participación protagónica y empoderamiento político. Sin duda, es valioso el protagonismo que en las luchas comunitarias tienen las mujeres; sin embargo, Venezuela está lejos del objetivo de alcanzar la paridad política, porque la presencia de mujeres en los espacios sustantivos del poder del Estado y la sociedad sigue siendo minoritaria. Además, la cualidad feminista de los liderazgos femeninos comunitarios es deficiente, porque se han enfocado más en luchas generales (optimización de los servicios públicos, la seguridad ciudadana, etc.) que en los derechos específicos de las mujeres (políticos, sexuales, reproductivos, entre otros).

En cambio, las posturas feministas que valoran más el reconocimiento de la diferencia y la ampliación del concepto de la política, sin ser totalmente antagónicas con lo planteado por el feminismo de la igualdad, reconocen que en Venezuela se ha dado una verdadera revolución en materia de participación política de las mujeres, una revolución que ha impactado la vida cotidiana, ya que cientos de miles de venezolanas han asumido la conducción política en miles de comunidades y procesos capilares de la sociedad. De este modo, se ha constituido un fenómeno sustantivo de feminización de la política, que ha incorporado nuevos códigos y que, sin duda, es la principal base de sustentación social-territorial del proceso político vivido en el país durante los últimos 20 años. Aun cuando estas lideresas comunitarias no se reconozcan explícitamente como feministas, su empoderamiento político colectivo ha permitido que la perspectiva de las mujeres transversalice buena parte de sus luchas generales, tomando en consideración algunos de sus derechos como sujeto social. 
Por lo tanto, desde esta mirada feminista, la profundización democrática pasa por el acceso y reconocimiento de los aportes de las mujeres a la sociedad, ya que el feminismo no plantea simple igualación con los hombres, sino reconocimiento hacia la feminización de la sociedad, es decir, el reconocimiento de los aportes propios de las mujeres, desde una praxis histórica que ha estado al margen, pero que tiene su propia contribución a otras formas de entender y vivir las relaciones sociales en todos los ámbitos.

Las mujeres venezolanas pueden intentar desafiar con su acción protagónica la condición de subordinación que les ha atribuido el patriarcado; sin embargo, más allá de los aspectos declarativos, tienen una agenda política que ha sido pospuesta en los últimos años, dando lugar al cuestionamiento del carácter feminista del proyecto emancipador que las convocó a volcarse a las calles y asumir roles estelares en la organización y en la vanguardia del pueblo. Las participación protagónica requiere importantes niveles de articulación (no de regulación), que permitan expresar las experiencias locales de construcción popular, en una agenda nacional y global, capaz de representar globalmente - sin universalizar ni homogeneizar - los intereses de las mayorías de las mujeres venezolanas.

Reconocer la participación protagónica de las mujeres en Venezuela y sus transformaciones, especialmente a la luz de las expresiones organizativas emergentes, que se manifiestan principalmente en la organización popular y la organización pública-institucional, plantea desafíos importantes, principalmente frente a la necesidad de incidir de forma radical en todos los ámbitos del saber y del poder, para coadyuvar de manera sustantiva a la democratización del poder político; en palabras de Pateman (1983):

Lo que estas páginas pretenden es [...] mostrar que el feminismo le presenta hoy a la democracia su desafío más importante y su crítica más amplia: tanto a la democracia en su forma liberal actual, como en cualquier forma futura, sea ésta participativa o autogestiva. (p.3)

No obstante, no hay una posición homogénea por parte de las diversas corrientes del feminismo en relación con estos temas; no hay una respuesta unívoca respecto a temas medulares como democracia, participación protagónica, organización y cómo se ha ido construyendo ciudadanía bajo un enfoque feminista. De acá se desprende el objetivo fundamental de estudiar cómo se ha desarrollado la participación protagónica de las mujeres en el proceso democrático venezolano, las diversas formas de organización que han surgido en los últimos 20 años en el país y cuánto se ha podido avanzar en el ejercicio pleno de su ciudadanía. Esto es relevante en un contexto donde, de acuerdo con la Comisión Económica para América Latina y el Caribe (CEPAL, 2012), en la región se sigue registrando una baja calidad y profundidad de la democracia.

Hoy resulta evidente que "como el capitalismo no ejerce su dominio sino sirviéndose de otras formas de opresión, principalmente del colonialismo y el patriarcado, esta democracia radical, además de anticapitalista, debe ser también anticolonialista y antipatriarcal" (De Sousa-Santos, 2018, p. 491). 
A nuevas formas de democracia han emergido nuevas formas de ciudadanía; a mayor participación, mayor organización, y a mayor organización, mayor participación protagónica y consciente. En este momento histórico, feminizar la política es importante, en tanto se realice acompañada con la cualidad feminista, pues si bien en cierto que las mujeres han accedido de forma masiva a escenarios públicos de participación en los últimos años, son lentos los cambios producidos en el sistema de género.

\section{$\mathbf{R}_{\text {eferencias }}$}

Aguirre, V. (2018). Empoderamiento económico de las mujeres. Estrategias para superar la feminización de la pobreza. Caracas: Fundación Editorial El perro y la rana.

Carosio, A., \& Vargas-Arenas, I. (2010). Feminismo y socialismo. Caracas: Fundación Editorial El Perro y la Rana.

Carosio, A. (2012). Feminismo y cambio social en América Latina. Buenos Aires: CLACSO.

Comisión Económica para América Latina y el Caribe (CEPAL). (2012). El Estado frente a la autonomía de las mujeres. Santiago de Chile: Naciones UnidasCEPAL 2012.

Congreso Venezolano de las Mujeres. (2015). Documento base para el debate plataforma unitaria de lucha de las mujeres patriotas y revolucionarias. Caracas. Recuperado de: http://www.prensaindigena.org/web/pdf/Congreso $\% 20$ Venezolano.pdf

Constitución de la República de Venezuela. (1961). Recuperado de: http:// www.cervantesvirtual.com/obra-visor/constitucion-de-la-republica-devenezuela-23-enero-1961/html/

Constitución de la República Bolivariana de Venezuela. (1999). Publicada en Gaceta Oficial N. ${ }^{\circ} 5.908$ [extraordinaria], 19 de febrero de 2009. Caracas: Ediciones de la Asamblea Nacional. Recuperado de http://www.minci.gob. ve/wp-content/uploads/2011/04/CONSTITUCION.pdf

Delgado, L. R. (2017). El rostro de la mujer venezolana. 1936 - 2016. Caracas: Fondo Editorial El Hormiguero.

De Sousa-Santos, B. (2018). Construyendo las epistemologías del Sur: para un pensamiento alternativo de alternativas, Vol. II. Buenos Aires: cLAcso.

Di Marco, G. (2011). El pueblo feminista. Movimientos sociales y luchas de las mujeres en torno a la ciudadanía. Buenos Aires: Biblos. 
Dussel, E (2011). Política de la Liberación. Volumen II. Arquitectónica. Caracas: Fundación Editorial El Perro y la Rana.

Falcón, L. (2000). Mujer y poder político. Madrid: Kira Edit.

García-Prince, E. (2012). La participación política de las mujeres en Venezuela: situación actual y estrategias para su ampliación. Caracas: Instituto Latinoamericano de Investigaciones Sociales.

García-Linera, A. (2011). La potencia plebeya. Acción colectiva e identidades indígenas, obreras y populares en Bolivia. La Habana: Fondo Editorial Casa de las Américas.

García-Linera, A. (2014). Democracia, Estado, Nación. La Paz: Vicepresidencia del Estado Plurinacional de Bolivia.

Madriz-Franco, R. E. (2017). Las necesarias políticas inclusivas de género en el seno de la fanb. Revista Venezolana de Estudios de la Mujer, 22(48), 103-114.

Martínez-Palacios, J. (2018). ¿Qué significa participar? Reflexiones sobre la construcción de las imágenes de la participación. PAPERS, Revista de Sociología, 103(3), 367-393. Dor: http://dx.doi.org/10.5565/rev/papers.2319

Ministerio del Poder Popular para la Mujer y la Igualdad de Género. (2013). Plan de Igualdad y Equidad de Género Mamá Rosa [2013-2019]. Caracas: Ministerio del Poder Popular para la Mujer y la Igualdad de Género.

Monedero, J. C. (2012). El gobierno de las palabras. Política para tiempos de confusión. Caracas: Centro Internacional Miranda, Fondo Editorial de Cultura Económica de España.

Paredes, J. y Guzmán, A. (2014). El tejido de la rebeldía ¿Qué es el feminismo comunitario? Bases para la despatriarcalización. La Paz: Mujeres Creando Comunidad.

Ministerio del Poder Popular para la Comunicación y la Información. (2009). Proyecto Nacional Simón Bolívar. Líneas generales del Plan de Desarrollo Económico y Social de la Nación 2007-2013 (2. ㄹ edición). Caracas.

Plan de la Patria. Segundo Plan de Desarrollo Económico y Social de la Nación 20132019. (2013). Gaceta Oficial Extraordinaria de la República Bolivariana de Venezuela N.ํㅜ 6.118 Extraordinario, 4 de diciembre de 2013.

Proyecto Nacional Simón Bolívar, Tercer Plan Socialista de Desarrollo Económico y Social de la Nación 2019-2025. (2019). Gaceta Oficial Extraordinaria de la República Bolivariana de Venezuela N. ${ }^{\circ} 6.446$ Extraordinario, 8 de abril de 2019. 
Scott, J. W. (2012). Las mujeres y los derechos del hombre. Feminismo y sufragio en Francia, 1789-1944. Buenos Aires: Siglo XXI Editores.

Silva-Charvet, E. (Edit.) (2005). Identidad y ciudadanía de las mujeres. Quito: Ediciones Abya-Yala.

Vargas Arenas, I. (2007). Historia, mujer, mujeres. Origen y desarrollo histórico de la exclusión social en Venezuela. El caso de los colectivos femeninos. Caracas: Fundación Editorial El Perro y la Rana.

Vargas-Arenas, I. (2010). Mujeres en tiempos de cambio. Reflexiones en torno a los derechos sociales, políticos, económicos y culturales de las mujeres venezolanas. Caracas: Archivo General de la Nación/Centro Nacional de Historia.

Vargas-Arenas, I., \& Sanoja-Obediente, M. (2015). La marcha hacia la sociedad comunal. Tesis sobre el socialismo bolivariano. Caracas: Fundación Editorial El Perro y la Rana. 